\title{
ARTICLES
}

\section{Services of the Central Education Library of the Peel Board of Education serving graduates at Brock University and the Extension Campus of the Ontario Institute of Studies in Education: A Survey. By Catherine E. Wilkins}

\begin{abstract}
The setting for this study was the J.A. Turner Professional Library which is the central corporate Professional Library for the Peel Board of Education which is the largest Public School Board in Canada located west of Toronto encompassing Mississauga, Brampton and Caledon. The library also provides library services for educators in graduate programs at Brock University, St. Catharines, and the extension campus Park Royal, the Ontario Institute for Studies in Education at the University of Toronto, York University, Toronto, and the Faculty of Education University of Toronto to support their professional development and continuing education needs. The focus for the study were the Peel and Brock consumer groups to allow for comparison. The purpose of this study was to evaluate the services and resources of the J.A. Turner Professional Library by ascertaining the views and opinions of these two consumer groups. The data collection consisted of a self-reporting questionnaire and selectedinterviews. The results indicate that there is a high level of support for the J.A. Turner Professional Library. The interviews provided future directions for the development of the J.A. Turner Professional Library. The study closes with a series of recommendations to enhance the operation of the J.A. Turner Professional Library within the organizational context of the Peel Board of Education.
\end{abstract}

\section{Overview of The Peel Board of Education}

The Peel Board of Education (herein referred to as the Board) is the largest public school board in Canada located west of Toronto encompassing Mississauga, Brampton and Caledon and is continuing to expand. To date, there are 140 elementary schools and 30 secondary schools with a total of 94,893 students. There are 70,000 learners served by continuing education. It is estimated that by the year 2001 our number of schools will be 211 with a total student population of 111,000 .

\section{Context of the J.A. Turner Professional Library}

The J.A. Turner Professional Library (herein referred to as the Professional Library) is the central corporate Professional Library for the Board. The library also provides services to Peel educators continuing their professional development while studyingat BrockUniversity, St. Catharines, and the extensioncampus Park Royal, the Ontario Institute for Studies in Education at the University of Toronto, York University, Toronto, and the Faculty of Education University of Toronto.
The primary objective of the Professional Library is to provide library and information services to Board teaching, resource and administrative staff. Over the years this service has evolved to include comprehensive literature searches, reference searches, document procurrent services, distribution of the Board curriculum documents, bibliographic documents, copyright clearance and extensive networking with education libraries including school board libraries, libraries of institutions of higher learning, government libraries, educational association's special collections and educational consortiums to extend information resources and sharing.

\section{Staffing Complement}

Currently the Professional Library is staffed with ten individuals: four are full-time, and six are part-time temporary assistants. The staff complement includes one Professional Librarian, two information resources technicians, a library secretary and six library student assistants. 


\section{Introduction}

In our information based society it has become axiomatic that information is a valued commodity. Libraries are an integral subset of the total information system. Libraries are especially valuable for academia and this value can be generalized to education at large.

The purpose of this study was to evaluate the services and resources of the Professional Library by ascertaining the views and opinions of two consumer groups of the professional library at the Board. The focus for the study was the Board and Brock consumer groups so as to allow for comparisons. One of which are the stakeholders including: (Board administration and school support services staff and Brock University Full-time Faculty) and the actual users such as students, teachers, resource staff, administrators, and administrative staff. It should be noted these two groups are not mutually exclusive. Individuals may fall into each of, or both categories in the natural course of their role at the Board.

Specifically, the evaluation addressed the following general questions.

1. Which of the services of the Professional Library do you like best?

2. Which of the services of the Professional Library would you like to see improved?

3. To what extent are the resources of the Professional Library useful for your information needs?

4. Which resources of the Professional Library would you like to see enhanced?

5. What future changes would you like to see in:

(a) This library

(b) Any professional library?

These generic research questions were developed by analyzing the library's objectives. The author was looking for ways to ensure quality in terms of accessibility, services, and resources of the library. Parallel to this the author was also looking for ways to enhance or improve these three aspects in keeping with the current organizational renewal initiatives i.e., strategic planning which is the Board commitment. The author was also cognizant of the changing roles of libraries in our information society as identified in the literature and intends to be proactive in terms of the evaluation plan for the Professional Library in keeping with the Stufflebeam model (1971) for evaluation in large bureaucratic organizations for decision-making. Stufflebeam (1971) following Tyler (1949) states that the evaluation plan can only begin once the objectives are clarified. Tyler (1949) stresses that the objectives must be simple statements with measurable results/outcomes. Russell (1990) defines this as the list of items for the intended curriculum program objectives. Stufflebeam (1971) identifies four types of evaluation including: context, input, process and product. Context evaluation has the two contrasting components of contingency and congruence.

This was the structure for the evaluation plan for the Professional Library. Stufflebeam's (1971) plan was based on the researcher having credibility within the organization and thus being sensitive to proper data gathering within theoretical sampling. The two groups chosen should generate data to allow comparisons. Treatment of the two consumer groups will require particular sensitivity on the part of the researcher owing to their natural intersection. Glaser and Strauss (1967) also contend that if the data is grouped into well-grounded categories, comparative materials will feed hypotheses from which generalized theory will emerge. Again Russell (1990) concurs, recommending clarification of the objectives to create a list of the items for the intended curriculum. The items in the list became the categories for investigation or comparison. The categories must be identified based on the objectives, the relevancies in the data (saturation), and the researcher's knowledge of the context of the evaluation.

\section{Review of The Literature}

\section{Introduction}

The purpose for the evaluation of the Professional Library was grounded in the belief that as a service component within the organization i.e., the Board, the library is charged with the responsibility of ensuring that its objectives fit the organizational culture, i.e. information needs in terms of library services, resources and accessibility. The organization is in a period of renewal and the library must renew alongside to ensure a vital role in the emerging culture. The literature of Brimseck (1989), Russell (1990), Sy and Walther (1989), and Willard and Morrison (1988) reveals that this library and libraries in general, are responsible for ensuring that their objectives are what the organization demands.

This review of the literature will examine issues that have impact on the role of libraries and librarians in our changing society. In the literature, there are several prevalent issues or themes which have been utilized for organization of the review. These issues include: emerging technology, and professional renewal. Each one contributes to our general social values shift from the 1950s industrial model where homogeneity was valued and now in the 1990s heterogeneity is valued. The literature appears to recommend that one must look to past events in order to think about the future.

\section{Emerging Technology}

Most authors recognize that the accelerated development of new technology will have impact on libraries. There is argument also in the principle that libraries are stakeholders in the development of new technology. This concept is not new as Stanton identified technology has been important to libraries since the Alexandrian library. Random House defines technology as the tools of the society that one utilizes to accomplish work. This concept of technology remains today. However, by accelerated 
impact one will see changes in the way in which librarians work and interact with clients (Spaulding 1988).

Senese (1984) notes that according to Toffler's observations, contrary to the common intellectual explanation that technology would deprive us of our individuality, the opposite has occurred and the contribution of the individual is valued and protected as seen by Freedom of Information and Protection of Privacy legislation. Evidence exists in commerce where mass marketing has given way to market segmentation and in communications where broadcast networks have been superseded by cable systems.

Rider (1989) who criticized libraries for failing to integrate sources in the past believes the new technologies will change the form of information (e.g. Machine Readable Data Files) and provide the impetus for libraries to begin again. His criticism regarding the failure to integrate is an issue identified also by Black (1986). Black (1986) stresses the importance of the integration of library collection development functions, i.e., serials management, acquisitions, and cataloguing in order to provide an accurate reflection of information holdings for patrons all of which are implemented with the new technologies. DeGennaro (1982) also supports the concept of integration to develop the "electronic library" following from his perspective that the new technologies will serve to enhance libraries in a fashion similar to the impact of the Gutenberg's moveable type in 1437.

In terms of the impact of change, changes to work and patron librarian interaction are identified by Spaulding, Ojala, DeGennaro, and Stanton who identify the new end-user systems. Ojala (1986) wisely states that this will be a limited group of library patrons. Spaulding (1988) supports this view and declares that patrons have emotional attachments to libraries and librarians and for practical reasons do not wish to do their own searches beyond a cursory level. They want interpretation including analysis and synthesis of information. Schuman (1990) also concurs. In her analysis she believes that librarians must be cognizant of theirsocial responsibility to facilitate understanding through knowledge and not swallow the current fantasies of 1) access to excess, 2) information digopoly, 3) full-text fantasy, and 4) business fantasy which are evident in the media. Librarians have vital roles as problem-solvers and must be proactive with regard to future technological developments for libraries. If one listens to the media, it is easy to be subsumed by the four fantasies which are an over simplification of reality. Librarians have a responsibility to shape the destiny of information systems.

\section{Professional Renewal}

The literature reviewed identified implicitly and explicitly the need for continuous professional renewal on the part of librarians. Spaulding (1988), DeGennaro (1982) and Schuman (1990) indicate that professional development is required for librarians to be productive with regard to technology and the evolving social role of libraries. Professional renewal will be required to cope with our changing society, sophisticated patrons, changing organizational roles, growing library networks, and changes in research. Graham (1989) noted that if we support the premise that our society is becoming a learning society, librarians will be continually renewing themselves to meet the needs of their patrons.

In summary, the review of the literature reveals common themes are emerging with regard to the role of libraries and librarians. As discussed, they focus on changes resulting from the emerging information society, accelerated development of technologies, and the importance of professional renewal for librarians. The author also notes that much of the literature reviewed reflects on history as a method of projecting future needs. The literature stresses the continuing importance of libraries and librarians for their contributions to society regarding the preservation and dissemination of knowledge to all.

In criticism of the literature there is much attention given to the labelling of librarians current and future roles. The authors DeGennaro (1982), Spaulding (1988) and Schuman (1990) utilize the labelling process as a method of analysis. Stanton (1989), on the contrary, utilizes the labelling process as a marketing approach.

\section{Conclusion}

It is evident that the majority of authors support the contentions expressed in the literature regarding societal change, technological developments and professional renewal. However, as our society evolves into the information society, we must be ever cognizant of our values as librarians and the social responsibility of libraries.

Libraries will continue to require standards to perform information functions and services and increasingly will rely on interlibrary cooperation. Librarians will be continually faced with change and as professionals must be proactive in order to uphold our social responsibilities and continue to support individuals in an interpretive role. It is clear from the literature and professional observation that more will be required in terms of interpretation of needs, and analysis and synthesis of information into relevant packages. Increasingly, as we face change, we must also be perceived as being open and flexible to information needs of patrons in order to perform our interpretive role. All changes will be challenging and rewarding to the library community.

\section{Methodology}

\section{Population and Sample}

The population for this survey consisted of four distinct groups. First, all academic employees including teachers, officers, consultants made up the first stratification of the sample. Students currently enrolled in Brock University's Master of Education program who utilize the library's services comprised the second level. All senior administration (superintendents, regional superintendents, senior executive and program coordinators) made up the third level. The fourth distinct group was Brock full-time faculty who utilize the library and encourage their students to do so.

The four distinct groups were then combined into two consumer groups, i.e, stakeholders and users for comparison 
based on the researchers' knowledge of their expectations and usage of the library. The stakeholders were interviewed by the principal investigator and the users were surveyed.

\section{Sampling Frame}

In this section, the method of selecting the sample is described. From the overall population, the individuals were categorized into those who utilize the library and those who do not.

For the first group, only those who have been using the library services were surveyed.

From the list of Brock students a sample of 50 students were selected at random to be surveyed.

For the third group, only those who use the library services were interviewed with one exception - that is, all program coordinators were interviewed. For the fourth group only Brock full-time faculty who use the library services were interviewed. Seventy percent of the Peel users responded and forty-two percent of the Brock users responded.

The population included: 800 Peel users, 50 Brock users and 38 Peel stakeholders and 16 Brock full-time faculty stakeholders.

Table 1: Summary of Sample

\begin{tabular}{llc}
\hline Group & Sample & $\begin{array}{c}\text { Response } \\
\text { Rate }\end{array}$ \\
\hline $\begin{array}{l}\text { Users } \\
\text { Peel }\end{array}$ & 127 & $76 \%$ \\
Brock & 50 & $42 \%$ \\
$\begin{array}{l}\text { Stakeholders } \\
\text { Administration }\end{array}$ & 16 & $100 \%$ \\
$\begin{array}{l}\text { Coordinators } \\
\text { Brock full-time } \\
\text { faculty }\end{array}$ & 16 & $100 \%$ \\
\hline
\end{tabular}

\section{Instrumentation}

\section{Survey Questionnaire}

The content of the questionnaire requested users to rate the services, resources and accessibility of the Professional Library. These primary themes were identified after analysing the library objectives. The investigator was interested in improving these areas (i.e., accessibility, services, resources) of the Professional Library and wanted to see how effective they are presently, i.e, congruence Stufflebeam (1971) "How well is the intended curriculum being taught and what is actually attained?"

In each of the questions regarding the services, the resources and the accessibility (communications) the investigator pre- sented defined categories and examples for the user to rate. It is intended that these categories will be logical variables or components for comparison. The initial question required the users to identify their purpose for utilizing the library and again the response categories have been clearly defined for comparison. The questions move from the general to the specific in each of the three aspects to assist the respondents to focus their thinking for each specific category. There is an area for open-ended comments regarding any aspect of the Professional Library. This has been included because the principal investigator was aware that in the context of the organization the respondents are writers and will add valuable information when questioned openly. The questionnaire closes with an invitation for those interested in furtherdiscussion in focus groups to leave their name. Appendix A contains the questionnaire.

\section{Stakeholders - Interview Schedule}

The major themes (services, resources, accessibility) contained in the questionnaire have been formatted for the group of stakeholders and are presented in part two of the article. The interviewees were asked to rate the same services and resources as appear in the questionnaire. The principal investigator handed each interviewee the chart with the categories and examples of services and resources. It is intended that this will promote discussion, and educate the stakeholder regarding the themes as they generally are unaware of the complexities of the library because they receive full service without utilizing each of the areas themselves.

The interviewees were asked to comment on what they see as the future role of the Professional Library in the Board and the future role of libraries in society at large.

\section{Data Collection}

\section{Stakeholders}

Each of the stakeholders was interviewed on site at the H.J.A. Brown Education Centre at their convenience. Letters of introduction and thank you were sent. Copies of the letters of introduction and thank you were included in the appendices.

\section{Users}

Using the Board courier system, the questionnaire was forwarded to the respective school sites. Throughout this study, the Board Research Department reviewed the instrumentation and provided collegial support to ensure that the study was conducted according to the Board policy and provided an objective perspective. There were two follow-up letters sent as required.

\section{Data Analysis}

The data originating from the users questionnaire was entered on to a personal computer for analysis. Descriptive fre- 
quencies and contingency analyses were performed on the data.

The interview data was coded and summarized by the principal investigator. The interview data which was analyzed included transcriptions of the interviews of the stakeholders who were interviewed. The stakeholders as described earlier fall into three groups that are not mutually exclusive. These three groups include: Peel Board Senior Administration and Superintendents, Program Department Co-ordinators, and Brock full-time faculty all of whom utilize the library.

The analyst utilized the grounded theory building methodology of Glaser and Strauss (1967) to analyse the qualitative interview data. Glaser and Strauss' (1967) methodology called for joint coding and analysis in a systematic approach which also utilizes theoretical sampling. This methodology allows for creative generating of theory. It is known as the Constant Comparative Method and includes the following four steps:

1) comparing incidents applicable to each category

2) integrating categories and their properties

3) delimitating the theory

4) writing the theory.

Constant comparison following Glaser and Strauss (1967) generated theoretical properties or components for each category of analysis. Each of the three groups of interviewees including Peel Senior Administration and Superintendents, Program Department Co-ordinators, and Brock full-time faculty were analyzed as a broad category following from comparison of the data, and the instrument for data collection (i.e., interview schedule) further categories and components or properties for comparison were generated. The data from each interview group was analyzed distinctly according to the theoretical sampling process, however, the categories for comparison were the same for each group. These results were summarized in commentary form which was compared further for reduction as the analyst expected to uncover underlying uniformities. The results from the groups were then compared for thematic similarities and dissimilarities.

\section{Results}

\section{Introduction}

In this article the results of the library survey will be presented in a number of ways. First, frequencies and descriptive statistics will be given. Second, the survey data will be recoded into three categories and contingency analysis including chisquare tests will be summarized. Third, the results of the interviews will be summarized and presented in anecdotal format in part two of this article.

\section{Profile of the Users}

Recall that the sample included two distinct groups who were identified as users of the Professional Library. The two groups included Peel teachers and Brock students who were queried as to their reasons for using the library. Sixty-three percent of Peel teachers and $95 \%$ of Brock students identified continuing education as the reason. Eighty-five percent of the Peel teachers and $48 \%$ of the Brockstudents noted that they used the library for professional development activities. Browsing current literature was also mentioned by a substantial number of respondents (Peel 54\%; Brock 27\%). Other reasons for using the library included workshop preparation (Peel 53\%; Brock 14\%); committee work (Peel 42\%; Brock 24\%); and classroom preparation (Peel 17\%; Brock 5\%); respectively for Peel teachers and Brock students.

\section{Level of Satisfaction with the J.A. Turner Professional Library}

For the next section the respondents were asked to rate their level of satisfaction on three dimensions of the library. The results are presented in Table 2 . The results reveal that there is a high level of overall satisfaction from both groups with the three dimensions of the library ( $70 \%$ to $100 \%)$.

Table 2: Summary of Percentages of Overall Level of Satisfaction for the J.A. Turner Professional Library

Peel

Brock

Overall Services Level of Satisfaction Level of Satisfaction

\begin{tabular}{lcccccccccc}
\hline & \multicolumn{1}{c}{ Low } & \multicolumn{4}{c}{ High } & \multicolumn{4}{c}{ Low } & \multicolumn{4}{c}{ High } \\
& 1 & 2 & 3 & 4 & 5 & 1 & 2 & 3 & 4 & 5 \\
\hline Services & 2 & 1 & 8 & 19 & 69 & 0 & 0 & 0 & 30 & 70 \\
Resources & 1 & 6 & 22 & 40 & 30 & 0 & 0 & 19 & 52 & 29 \\
Accessibility & 4 & 4 & 14 & 23 & 54 & 0 & 0 & 19 & 38 & 43
\end{tabular}

\section{Level of Satisfaction}

To complete this section, respondents were asked to comment in an open-ended response. The Peel teachers commented slightly less than the Brock students (40\% to $48 \%$ ) respectively. The comments from the Peel and Brock respondents were positive in nature and consistently mentioned the overall effectiveness of the library in terms of services, staff and resources $(57 \%$ and $60 \%$ ), respectively. They also requested that the library expand its services, collections and hours (24\% and 30\%), respectively. The Peel teachers identified concerns relating to accessibility and system awareness (13\% and $10 \%)$. Some Peel respondents indicated that their use of the library was infrequent (6\%).

\section{Rating of Services}

For the next section, the respondents were asked to rate their level of satisfaction with the various services provided by the Professional Library. The services were categorized under the following headings: search services, document delivery services, staff assistance, library orientation and other services. The results are presented in Table 3. In terms of search services, the results reveal that there is a high level of satisfaction in each of 
the categories (84\% to $100 \%)$. The document delivery services are also rated highly by both groups of users (88\% to $93 \%$ ). Staff assistance is also rated highly by both groups ( $83 \%$ to $100 \%$ ). Similarly, library orientation and other services are rated highly by the respondents (85\% to $94 \%$ ) and (78\% to $100 \%)$ for Peel and Brock, respectively. Overall, the Brock students tend to rate the services higher than the Peel teachers.

Table 3: Summary of Ratings of Services

Peel

Services
Brock

Level of Satisfaction

\begin{tabular}{llllllllll} 
Low & & & \multicolumn{3}{l}{ High } & Low & & \multicolumn{3}{c}{ High } \\
1 & 2 & 3 & 4 & 5 & 1 & 2 & 3 & 4 & 5
\end{tabular}

Search Strategy Design

Educational Literature Searches

Current AwarenessSearches

Reference Services

Document Delivery Service

Interlibrary Loan

ERIC Document Acquisition

Journal Article Acquisition

\section{Staff Assistance}

Strategy Design

Retrieval In-house

External Information

Library Orientation

Online Public Access

CD ROM ERIC

Other Services

Copyright Clearance

Curriculum distribution

$\begin{array}{lllll}0 & 2 & 9 & 27 & 63 \\ 1 & 0 & 4 & 17 & 76 \\ 0 & 13 & 32 & 55 & 0 \\ 2 & 2 & 5 & 31 & 61\end{array}$

$\begin{array}{lllll}2 & 2 & 18 & 24 & 55\end{array}$

$\begin{array}{lllll}1 & 1 & 7 & 27 & 63\end{array}$

$\begin{array}{lllll}0 & 1 & 12 & 28 & 59\end{array}$

$\begin{array}{lllll}0 & 0 & 8 & 21 & 71 \\ 0 & 1 & 11 & 16 & 72 \\ 3 & 3 & 11 & 16 & 67\end{array}$

$\begin{array}{lllll}0 & 3 & 13 & 44 & 41\end{array}$

$\begin{array}{lllll}0 & 0 & 6 & 31 & 63\end{array}$

$\begin{array}{lllll}4 & 4 & 4 & 37 & 52\end{array}$

$\begin{array}{lllll}0 & 0 & 0 & 43 & 57 \\ 0 & 0 & 11 & 26 & 63 \\ 0 & 0 & 0 & 10 & 0 \\ 0 & 0 & 9 & 36 & 55\end{array}$

\section{Summary of Rating of Usefulness of Resources}

For the next section, the respondents were asked to rate the usefulness of specific resources. The results are presented in Table 4. Generally both groups of respondents rated the resources highly and the Brock users rated the resources more favourably. The book collection was given the lowest rating by both groups (52\% to 69\%) for Peel and Brock, respectively. The ERIC CD-ROM was given the highest rating by both groups (95\% to 100\%) for Peel and Brock, respectively.

\section{Summary of Level of Satisfaction with Communications Aspects of the J.A. Turner Professional Library}

For the next section, the respondents were asked to rate their level of satisfaction with the communications aspects of the library. The results are presented in Table 5. Generally both groups of respondents are satisfied with the communication aspects of the library. The provision of information i.e., making the system aware of its services is given the lowest level of $-10$ satisfaction by both groups (37\% to $76 \%$ ) for Peel teachers and Brock students, respectively. Both respondent groups indicated that they receive the highest level of satisfaction with regard to the knowledgeable personnel (94\% to $100 \%$ ) for Peel teachers and Brock students, respectively.

To close the survey, the respondents were asked to comment in an open-ended format regarding any aspect of the Professional Library. The Peel teachers commented more frequently than the Brock students (56\% and 24\%) respectively. The comments are positive in nature and consistently mentioned the overall effectiveness of the library with regard to its services, staff assistance, and resources (65\% and 60\%) for Peel and Brock respondents, respectively. Some Peel respondents requested that the library be expanded in terms of services and collections (17\%). The concerns identified related to hurn-around time and staff assistance (9\% and $20 \%$ ) for Peel and Brock respondents, respectively. Some Peel teachers' comments were of a more general nature and stated that the library services and communications had improved during their use of the library. 
Peel

Brock

Resources Level of Satisfaction Level of Satisfaction

\begin{tabular}{|c|c|c|c|c|c|c|c|c|c|c|}
\hline & \multicolumn{2}{|c|}{ Low } & \multicolumn{3}{|c|}{ High } & \multicolumn{2}{|c|}{ Low } & \multicolumn{3}{|c|}{ High } \\
\hline & 1 & 2 & 3 & 4 & 5 & 1 & 2 & 3 & 4 & 5 \\
\hline Reference Collection & 0 & 8 & 24 & 39 & 29 & 0 & 0 & 18 & 47 & 35 \\
\hline Book Collection & 4 & 10 & 35 & 29 & 23 & 0 & 6 & 25 & 50 & 19 \\
\hline Recent Acquisitions & 2 & 4 & 23 & 44 & 28 & 0 & 0 & 9 & 64 & 27 \\
\hline Curriculum Guidelines & 0 & 4 & 14 & 24 & 59 & 11 & 0 & 0 & 56 & 33 \\
\hline Resource Documents & 2 & 0 & 10 & 21 & 67 & 0 & 11 & 0 & 56 & 33 \\
\hline Peel Curriculum ${ }^{1}$ & 0 & 0 & 6 & 27 & 67 & 0 & 13 & 0 & 50 & 38 \\
\hline Self-serve CDROM & 5 & 0 & 5 & 32 & 59 & 0 & 0 & 0 & 64 & 36 \\
\hline ERIC & 0 & 0 & 5 & 28 & 67 & 0 & 0 & 0 & 50 & 50 \\
\hline Education Index & 0 & 2 & 2 & 32 & 63 & 0 & 0 & 0 & 55 & 45 \\
\hline ONERIS $^{2}$ & 0 & 0 & 7 & 21 & 71 & 0 & 0 & 0 & 57 & 43 \\
\hline Books in Print & 0 & 3 & 18 & 31 & 49 & 0 & 0 & 13 & 38 & 50 \\
\hline Ulrich's Guide & 0 & 0 & 0 & 42 & 58 & 0 & 0 & 0 & 100 & 0 \\
\hline Educational Journals & 5 & 2 & 9 & 28 & 57 & 0 & 0 & 0 & 62 & 38 \\
\hline Printed Abstracts \& Indexes & & & & & & & & & & \\
\hline Canadian Eduation Index & 0 & 0 & 9 & 43 & 49 & 0 & 0 & 8 & 50 & 42 \\
\hline Eduational Administration Abstracts & 0 & 13 & 37 & 50 & 0 & 0 & 0 & 8 & 50 & 42 \\
\hline Child Development Abstracts & 0 & 4 & 12 & 28 & 56 & 0 & 0 & 25 & 50 & 25 \\
\hline Psychological Bulletin & 0 & 0 & 17 & 26 & 57 & 0 & 0 & 17 & 67 & 17 \\
\hline
\end{tabular}

Table 5: Summary of Ratings of Usefulness of Resources

Peel

Communications Aspect Level of Satisfaction

\begin{tabular}{llllll}
\hline & \multicolumn{3}{c}{ Low } & \multicolumn{3}{c}{ High } \\
& 1 & 2 & 3 & 4 & 5 \\
\cline { 2 - 7 } & & & & & \\
Provision of Information & 11 & 21 & 30 & 25 & 12 \\
Direct Communication & 0 & 0 & 6 & 18 & 76 \\
Knowledgeable Personal & 0 & 1 & 5 & 23 & 71 \\
Indirect Communication & 1 & 1 & 15 & 29 & 54 \\
Delivery of Service & 2 & 5 & 15 & 25 & 52 \\
Quality of Service Received & 1 & 2 & 8 & 25 & 65
\end{tabular}

Brock

Level of Satisfaction

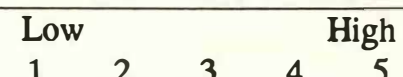

$\begin{array}{lllll}0 & 6 & 18 & 35 & 41 \\ 0 & 0 & 6 & 0 & 94 \\ 0 & 0 & 0 & 16 & 84 \\ 0 & 0 & 11 & 33 & 56 \\ 0 & 7 & 7 & 43 & 43 \\ 0 & 0 & 0 & 21 & 79\end{array}$




\section{Contingency Analysis}

It was of interest to determine if there were differences in response patterns between Peel teachers and Brock students. Consequently, the data was analyzed using contingency analysis (crosstabulation including chi-square). For the analysis, the five categories were collapsed into three with 1 and 2 being combined as well as 4 and 5. For this section only items which were significantly different are presented. The results yielded only three significant chi-squares (p. $<.05)$. These included the ratings of Journals articles acquisition $(x 2=7.72$, d.f. $=2, p=$ .02). As well as Peel Board Curriculum Documents (x2=7.0, d.f. $=2, \mathrm{p}=.03)$ and provision of information $(\mathrm{x} 2=9.51$, d.f. $=2, \mathrm{p}$ $=.009$ ). In all cases, the actual significance may be an artifact of the small samplesize. The convention of having five frequencies per cell has been violated and the small numbers probably account for the significant chi-square values.

\section{Forthcoming in Part Two of this Article}

The focus for part two of this article will be:

- the results of the interview data

- the summary and discussion of the study, and

- the recommendations.

\section{Bibliography}

Black, C. (1986). Quiet, Computer at Work. Georgia: Southwestern College. (ERIC Document Reproduction Service No. ED 281 526).

Brimsek, Tobi (1989). Portraits of Special Libraries From the Top: The Introduction. Special Libraries, 80(4) 258-263.

Brown, J.A., Jr. (1986). 2010: An Information Odyssey. Ohio: (ERIC Document Reproduction Service No. ED 282 568).

DeGennaro, R. (1982). Libraries, Technology, and the Information Market Place. Library Joumal, 107(11), 1045-54.

Dewey, John (1916). Democracy and Education. New York: Free Press (1966).

Glaser, B.G. \& A. C. Strauss. The Discovery of Grounded Theory Strategies for Qualitative Research. New York, NY: Aldine, 1967.

Graham, P.S. (1989). Research patterns and research libraries: What should change? College \& Research Libraries, 50(4),433-440.

Ojala, M. (1986). Views on End - UserSearching. Journal of the American Society for Information Science, 37(4), 433-440.

Rider, F. (1989). The Future of the Research Library. College and Research Libraries, 50(1), 49-55.

Riggs, Donald E., \& Sabine, Gordon A. (Eds.). Libraries In The 1990's. New York: Oryx Press.

Russell, Howard (1990). Research in Curriculum Evaluation. Department of Curriculum, Ontario Institute for Studies in Education, University of Toronto.

Schuman, G.P. (1990). Reclaiming Our Technological Future. Library Journal, 115(4), 34-38.

Senese, D.J. (1984). The New Role of the Librarian in the - 12
Information Age. Office of Educational Research and Improvement (ED). (ERIC Document Reproduction Service No. 273 275).

Spaulding, F.H. (1988). Special Librarian to Knowledge Counsellor in the Year 2006. Special Libraries, 79(2), 83-91.

Stanton, R.O. (1989). The Evolving Role of the Information Professional in Industry. Information Management Review, 5(2), 13-18.

Stufflebeam, Daniel L. Education, Evaluation and DecisionMaking. Ithasca, ILL: F.E. Peacock, 1971.

Sy,KarenJ. \& Walther, Peg (1989). Tracking Issues and Meeting Information Needs in Govemment Agency Libraries. Special Libraries, 80(3), 157-163.

Tyler, Ralph W. (1949). Basic Principles of Curriculum and Instruction. Chicago: University of Chicago Press, 1949.

Willard, Ann M. \& Morrison, Patricia (1988). The Dynamic Role of the Information Specialist: Two Perspectives. Special Libraries, 79(4), 271-276.

\section{APPENDIX A \\ J.A. TURNER PROFESSIONAL LIBRARY 1990 USER SURVEY}

The purpose of the survey is to elicit your feeling and opinions aboutthe J.A. Turner Professional Library. I am appealing to your generosity to take a few moments from your busy schedule to complete this brief questionnaire. It should take between 3 . 5 minutes to complete. Your anonymity and confidentiality are guaranteed. No individual will ever be identified, only aggregate responses will be presented. Would you please place the completed questionnaire in the self-addressed envelope and retum to me via the board's courier. Thank you very much for your support and cooperation. If you have any questions, lease do not hesitate to call me at 890-1099 ext 2602.

Please indicate you reasons for using the library: (select as many as appropriate) continuing education (ө.g., M.Ed., subject certification, Principal's, courses etc.)

professional development workshop preparation

committee work

classroom preparation

browsing current literature

Other reasons (please specify)

For each item, circle a number that best reflects your rating or level of satisfaction with the overall services provided by the J.A Tumer Library. For the ratings, a 1 is low and a 5 is high. If you are unsure or unable to rate your level of satisfaction please circle NA.

LOW

HIGH

$\begin{array}{lllllll}\text { Services } & 1 & 2 & 3 & 4 & 5 & \text { NA } \\ \text { Resources } & 1 & 2 & 3 & 4 & 5 & \text { NA } \\ \text { Accessibility } & 1 & 2 & 3 & 4 & 5 & \text { NA }\end{array}$




\section{Comments:}

Please rate your assessmentevaluation of the various services provided by the J.A. Turner Professional Library. Please circle NA if you are unsure or have not used the services.

LOW

Search Services

Search Strategy Design (ө.q., clarification of need)

Educational fiterature searches (ө.g., ERIC, ONTERIS)

Current awareness searches (ө.g., Globe \& Mall)

Subject specific literature searches (ө.g., science, medicine)

Reference senvices

(e.g., publisher Information)

Document Dellvery Services

Interlibrary loan

ERIC document acquisition Joumal article acquisition

\begin{tabular}{ccccccc} 
LOW & & & & & HIGH \\
\hline 1 & 2 & 3 & 4 & 5 & NA \\
1 & 2 & 3 & 4 & 5 & NA \\
1 & 2 & 3 & 4 & 5 & NA \\
1 & 2 & 3 & 4 & 5 & NA \\
1 & 2 & 3 & 4 & 5 & NA
\end{tabular}

Staff Assistance

$\begin{array}{llllllll}\text { Literature search strategy design } & 1 & 2 & 3 & 4 & 5 & \text { NA }\end{array}$

Retrieval of In-house items

Retrieval of external information

$\begin{array}{llllll}1 & 2 & 3 & 4 & 5 & \text { NA } \\ 1 & 2 & 3 & 4 & 5 & \text { NA } \\ 1 & 2 & 3 & 4 & 5 & \text { NA }\end{array}$

Lbrary Orientation

$\begin{array}{lllllll}\text { Online Public Access Catalogue } & 1 & 2 & 3 & 4 & 5 & \text { NA }\end{array}$

CD ROM ERIC

Oher Services

Copyright clearance

Curriculum distribution
In this section we are interested In some of the communications aspects of the professional library. Please circle the number that bests reflects your level of satisfaction with: (Circle NA if you are unsure)
HIGH

PROVISION OF INFORMATION: making the system aware of its service, its 1 availability, etc.

DIRECT COMMUNICATION - TELEPHONE OR FACE-TO-FACE: helpful, courteous,

$\begin{array}{llllllll}\text { getting } & 1 & 2 & 3 & 4 & 5 & \text { NA }\end{array}$ the run around, having your calks returned

knowledgeable personnel completed, memos, overdue slips, written

requests for information, letters, etc.

$\begin{array}{llllll}1 & 2 & 3 & 4 & 5 & \text { NA } \\ 1 & 2 & 3 & 4 & 5 & \text { NA }\end{array}$

DELIVERY OF SERVICE: turn around time,

completeness, conventence, etc.

QUALITY OF SERVICE RECEIVED: did the service

meet your expectations?

3

45

NA

Please feel free to comment on any aspect of the J.A. Turner Llbrary:

(e.g., best features, suggestions for Improvement)

If you are Interested In participating In a focus group for further discussion, please submit your name and location on the form provided.

Name:

Location:

Please rate the usefulness of the resources of the J.A. Turner Professionai Library. Please circe NA if you are unsure or have not used the resource.

THANK YOU

Resources

Reference Collection

Book Collection

Recent Acquisitions

Ministry of Education collection

- Curriculum guidelines

- Resource documents

Peel Board of Education curriculum documents

Self-senve CD ROM workstation

ERIC

Education Index

ONTERIS

Books In Print

Ulrich's Guide to Periodicals

Educational Journals Collection

Printed Abstracts and Indexes

Canadian Education Index

Educational Administration Abstracts

Child Development Abstracts

Psychological Bulletin

1

$\begin{array}{ll}1 & 2 \\ 1 & 2 \\ 1 & 2 \\ 1 & 2 \\ 1 & 2 \\ 1 & 2 \\ 1 & 2 \\ 1 & 2 \\ 1 & 2 \\ 1 & 2 \\ 1 & 2 \\ 1 & 2 \\ 1 & 2\end{array}$

2
2
2
2
2
2
2
2
2
2
2
2
2

3
3
3
3
3
3
3
3
3
3
3
3
3

NA

NA

NA

NA

NA

NA

NA

NA

NA

NA

NA

NA

$\begin{array}{lllll}2 & 3 & 4 & 5 & \text { NA } \\ 2 & 3 & 4 & 5 & \text { NA } \\ 2 & 3 & 4 & 5 & \text { NA } \\ 2 & 3 & 4 & 5 & \text { NA }\end{array}$

